\title{
Evaluation of Arenaria montana L. hydroethanolic extract as a chemopreventive food ingredient: A case study focusing a dairy product (yogurt)
}

\author{
Franciely S. Oliveira ${ }^{\mathrm{a}, \mathrm{b}, 1}$, Andreia Ribeiro ${ }^{\mathrm{a}, \mathrm{b}, 1}$, Lillian Barros $^{\mathrm{b}}$, Ricardo C. Calhelha ${ }^{\mathrm{b}}$, João C.M. Barreira ${ }^{\mathrm{b}}$, \\ Bogdan D. Junior $^{c}$, Rui M.V. Abreu ${ }^{b}$, Maria Filomena Barreiro ${ }^{\mathrm{a}, *}$, Isabel C.F.R. Ferreira ${ }^{\mathrm{b}, *}$ \\ ${ }^{a}$ Laboratory of Separation and Reaction Engineering - Laboratory of Catalysis and Materials (LSRE-LCM), Polytechnic Institute of Bragança, Campus de Santa Apolónia, 1134, \\ 5301-857 Bragança, Portugal \\ ${ }^{\mathrm{b}}$ Mountain Research Centre (CIMO), ESA, Polytechnic Institute of Bragança, Campus Santa Apolónia, 1172, 5300-253 Bragança, Portugal \\ ${ }^{\mathrm{c}}$ UTFPR, Universidade Federal Tecnológica do Paraná, Campus Campo Mourão Via Rosalina Maria dos Santos,1233, Campo Mourão, Paraná, Brazil
}

\section{A R T I C L E I N F O}

\section{Article history:}

Received 1 January 2017

Received in revised form 30 August 2017

Accepted 14 September 2017

Available online 20 September 2017

\section{Keywords:}

Arenaria montana

VEGFR-2 phosphorylation inhibition

Antiangiogenic potential

Functionalized yogurts

\begin{abstract}
A B S T R A C T
Natural ingredients are valuable options to be exploited in the design of innovative food formulations with health benefits. Therefore, it was evaluated the potential use of Arenaria montana L. hydroethanolic extract (rich in apigenin derivatives) as a chemopreventive agent in functional foods. Apigenin is recognized as inhibiting VEGFR-2, which is the key receptor involved in angiogenesis. The obtained extract was also able to inhibit the VEGFR-2 phosphorylation through an enzymatic assay $\left(\mathrm{IC}_{50}=\sim 63 \mu \mathrm{g} / \mathrm{mL}\right.$ ). Thereafter, free and microencapsulated forms were incorporated in yogurt. The obtained products maintained the nutritional value along the tested 3 days of storage, as also free sugars and fatty acids profiles, in comparison with the control samples. Nevertheless, the VEGFR-2 phosphorylation inhibition was not exhibited as intended. Even this behavior for the microencapsulated forms can be attributed to the protecting effect of the alginate matrix, further studies are required in order to better understand the shown performance.
\end{abstract}

(c) 2017 Elsevier Ltd. All rights reserved.

\section{Introduction}

The growth of new blood vessels from pre-existing ones is called angiogenesis, which is a fundamental process for embryonic development as well as normal tissue homeostasis (Patan, 2000). Under normal physiological conditions, there is a balance between stimulatory and inhibitory factors that regulates the process of angiogenesis (Fan, Yeh, Leung, Yue, \& Wong, 2006). However, in pathological cases, like tumor progression, the stimulation becomes excessive, resulting in the uncontrolled growth of new vessels, which facilitate tumor development and metastasis, through the production of abnormally large amounts of angiogenesis factors, such as VEGF (vascular endothelial growth factor) (Saghiri, Asatourian, Orangi, Sorenson, \& Sheibani, 2015). The VEGF is involved in the vascular permeability, as well as in the induction of endothelial cell proliferation, migration and survival, mainly

\footnotetext{
* Corresponding authors.

E-mail addresses: barreiro@ipb.pt (M.F. Barreiro), iferreira@ipb.pt (I.C.F.R. Ferreira).

${ }^{1}$ Both authors contributed equally.
}

through their membrane receptor tyrosine kinase VEGFR-2 (also known as KDR) (Soares et al., 2013).

It is recognized that diet contributes to more than $40 \%$ of the chronic angiogenic diseases (Losso, 2007). Nevertheless, foods are nowadays designed not only for nutritional purposes, but also to prevent diseases and to improve physical and mental well-being (Bigliardi \& Galati, 2013). Therefore, several studies have been conducted in order to identify functional foods active against excessive angiogenesis (Losso, 2007).

Plants are recognized as a source of bioactive compounds, for example phenolic compounds with reported antitumor properties (Stagos et al., 2012). Arenaria montana L., an herbaceous plant from the mountainous regions of southwestern Europe (Timité et al., 2011), contains apigenin derivatives, specifically apigenin 6- $C$-hexoside-8- $C$-hexoside, apigenin 6 - $C$-hexoside-8- $C$-pentoside, apigenin $\quad 2 "-O$-pentosyl-6- $C$-hexoside, apigenin-6- $C$-glucoside, apigenin $2^{\prime \prime}-O$-acetylpentosyl-6- $C$-hexoside and apigenin $2^{\prime \prime}-O$ feruloylhexosyl-6-C-hexoside (Pereira et al., 2014). Apigenin has received increasing attention due to its bioactive properties such as anti-inflammatory (Wang \& Huang, 2013), anti-mutagenic (Patel, Modi, Chiosis, \& Taldone, 2011) and, particularly, 
antiangiogenic and anticancer properties (Choudhury et al., 2013; He et al., 2015; Johnson \& Mejia, 2013). This flavone has shown the capacity to inhibit the cellular proliferation of several cancer cell lines such as hepatocellular (Kim, Jeon, \& Nam, 2011), pancreatic (He et al., 2015; Johnson \& Mejia, 2013), colorectal (Banerjee \& Mandal, 2015), multiple myeloma (Zhao et al., 2011) and leukemia (Budhraja et al., 2012), prevent the growth of new blood vessels (metastasis) (Osada, Imaoka, \& Funae, 2004), change the microenvironment of the cancer cells growth and reduce the cancer cells glucose uptake (Lefort \& Blay, 2013).

Although appreciated and consumed worldwide, yogurt is a product with limited amounts of bioactive compounds. This limitation can be overcome, by enrichment with natural extracts from plants or fruits, as proposed by some authors (Caleja et al., 2016; Martins et al., 2014). However, these extracts, which contain phenolic compounds and other bioactive molecules, most often are unstable under environmental and processing conditions, e.g. light, moisture, temperature and food matrix effects (Dias, Ferreira, \& Barreiro, 2015). Also, they might become inactive after being metabolized (Heleno, Martins, Queiroz, \& Ferreira, 2015). In this context, microencapsulation, a process through which the bioactive compound is entrapped or covered by a material, allows protection from these adverse conditions (Dias, Ferreira et al., 2015).

In the present study, the ability of $A$. montana hydroethanolic extract (rich in apigenin derivatives) to inhibit the phosphorylation of VEGRF-2 (enzyme involved in the angiogenesis process) was evaluated. Thereafter, the extract was microencapsulated using an atomization/coagulation technique with alginate as the encapsulating material. The obtained microspheres were characterized by optical microscopy (to inspect morphology and size) and the encapsulation estimated by HPLC-DAD. As a subsequent application step, the produced microspheres, as well as the free extract, were incorporated into yogurt samples in order to evaluate their role in functional dairy products with chemopreventive (antiangiogenic) potential.

\section{Materials and methods}

\subsection{Standards and reagents}

Sodium alginate was provided from Fluka Chemie (Steinheim, Switzerland) and calcium chloride di-hydrate was obtained from PanReac AppliChem SAU (Barcelona, Spain). For chromatographic analysis, HPLC-grade acetonitrile was acquired from Fisher Scientific (Lisbon, Portugal). Ethanol, used as solvent, was acquired from Pronalab (Lisbon, Portugal). The fatty acids methyl ester (FAME) reference standard mixture (standard $47885-\mathrm{U}$ ) was purchased from Sigma (St. Louis, MO, USA), as well as the sugar standards. Apigenin was obtained from Extrasynthesis (Genay Cedex, France) and sorafenib from Molekula (Newcastle, United Kingdom). Water was treated in a Milli-Q water purification system (TGI Pure Water Systems, Greenville, SC, USA). All other chemicals and solvents were of analytical grade and purchased from common sources.

\subsection{Plant species and preparation of the extract}

A. montana flowers and leafy stems (roughly the upper $15 \mathrm{~cm}$ of the dense clumps produced in spring) are commonly gathered to be used in traditional preparations. Samples were collected in full blossom along paths through oak trees. Voucher specimens were deposited at the Herbarium of the Escola Superior Agrária de Bragança (BRESA) according with Pereira et al. (2014). A sample for analysis was prepared by putting together the material from different specimens, thereafter lyophilized (FreeZone 4.5, Labconco,
Kansas City, MO, USA), reduced to a fine dried powder (20 mesh) and mixed to obtain homogeneity.

The hydroethanolic extract was prepared by stirring the sample ( $1 \mathrm{~g} ; 150 \mathrm{rpm})$ with $30 \mathrm{~mL}$ of an ethanol:water mixture $(80: 20, \mathrm{v} /$ $v)$, at room temperature, during $1 \mathrm{~h}$, and subsequently filtered thought a Whatman paper filter No. 4. The solid residue was reextracted under the same conditions and the obtained supernatant mixed with the one previously obtained. The ethanol of the combined extracts was removed by evaporation under reduced pressure (Büchi R-210, Flawil, Switzerland), while the water was eliminated by lyophilisation.

\subsection{VEGFR-2 enzymatic inhibition assay}

The A. montana hydroethanolic extract was assessed for VEGFR2 inhibition activity using the Z'-LYTE-Tyr1 Peptide assay kit (Invitrogen, Cat. PV3190), according to the procedure recommended by the manufacturer. Briefly, assays were performed with a total of $20 \mu \mathrm{L}$ in 384-well plates using the fluorescence resonance energy transfer technology. Each well plate was filled with $2.5 \mu \mathrm{L}$ of the tested extract in different concentrations, $5 \mu \mathrm{L}$ of VEGFR-2 solution and $2.5 \mu \mathrm{L}$ of ATP solution, and incubated during $1 \mathrm{~h}$ at room temperature. The development reagents $(5 \mu \mathrm{L})$ were then added to each well, followed by a stop reagent after a second incubation of $1 \mathrm{~h}$. The fluorescence was read at $445 \mathrm{~nm}$ and $520 \mathrm{~nm}$ (excitation $400 \mathrm{~nm}$ ) using a Biotek FLX800 micro-plate. Gen5 ${ }^{\mathrm{TM}}$ Software was used for data analysis. Sorafenib was used as positive control (Guimarães et al., 2016).

The results were expressed as $\mathrm{IC}_{50}$ values $(\mu \mathrm{g} / \mathrm{mL})$, which represent the concentration of the sample needed to inhibit $50 \%$ of the VEGFR-2 phosphorylation.

\subsection{Microencapsulation of the hydroethanolic extract and characterization of the microspheres}

\subsubsection{Microencapsulation}

The microspheres were produced by using an atomization/coagulation technique previously described by Martins et al., 2014; Dias et al., 2015 and Ribeiro et al., 2016. Briefly, the encapsulating material (calcium alginate) was formed by using sodium alginate and a calcium chloride $\left(\mathrm{CaCl}_{2}\right)$ as the coagulation agent (source of $\mathrm{Ca}^{2+}$ ions). The atomization solution was prepared by firstly mix $50 \mathrm{mg}$ of the A. montana extract with $10 \mathrm{~mL}$ of water. After complete dissolution, $400 \mathrm{mg}$ of sodium alginate were added and the preparation kept under stirring during $2 \mathrm{~h}$. To produce the microspheres, a NISCO Varj30 (Zurich, Switzerland) system, constituted by a pressure controller, gas source (nitrogen) and a syringe pump, was used. The previously prepared alginate solution containing the hydroethanolic extract was atomized using the following conditions: feed rate of $0.2 \mathrm{~mL} / \mathrm{min}$ and a nitrogen pressure of 0.1 bar. The atomized droplets upon in contact with the $\mathrm{CaCl}_{2}$ solution $(250 \mathrm{~mL}$ at concentration of $4 \%(w / v))$ coagulate promptly fixing the microspheres shape. For total consolidation, they remained in contact with the coagulation solution during $4 \mathrm{~h}$ under stirring at $200 \mathrm{rpm}$ at room temperature. Finally, microspheres were recovered by filtration under reduced pressure, washed twice with water $(100 \mathrm{~mL})$, lyophilized and stored in the dark.

\subsubsection{Characterization}

The microspheres formation was monitored during the coagulation step through Optical microscopy (OM) (initial and final times). The apparatus was a Nikon Eclipse 50i equipped with a camera (Nikon Digital Sight, Tokyo, Japan) for image acquisition. The encapsulation efficiency (EE) was evaluated by HPLC-DAD by quantifying the non-encapsulated apigenin derivatives, as identified in the work of Pereira et al. (2014). For that, the coagulation 
and the two washing solutions were analysed and the obtained responses summed. The encapsulation efficiency was then calculated according to the following expression:

$\mathrm{EE}=\left[\left(\mathrm{M}_{\mathrm{e}-\mathrm{t}}-\mathrm{M}_{\mathrm{e}-\mathrm{ne}}\right) /\left(\mathrm{M}_{\mathrm{e}-\mathrm{t}}\right)\right] \times 100$

in which $\mathrm{M}_{\mathrm{e}-\mathrm{t}}$ represents the theoretical amount of extract, i.e. the amount of extract used in the microencapsulation process, and $\mathrm{M}_{\mathrm{e}-\mathrm{ne}}$ corresponds to the non-encapsulated extract.

\subsection{Functionalization of yogurt with free and microencapsulated extracts}

\subsubsection{Preparation of the yogurt samples}

A natural yogurt with $5 \%$ fat was selected to test the incorporation of the free and microencapsulated A. montana extracts. Six yogurt portions, with $125 \mathrm{~g}$ each, were prepared: (i) two samples of the base yogurt (used as the control sample, i.e. without $A$. montana extract); (ii) two samples of yogurt with the free extract (16 mg each); (iii) two samples of yogurt with the microencapsulated extract ( $70 \mathrm{mg}$ of lyophilized microspheres each). All the prepared samples contain an equivalent amount of extract, either in its free or encapsulated form (the same equivalent ratio of $\mathrm{mg}$ extract/g yogurt). The used amount of extract was twice the $\mathrm{IC}_{50}$ value (obtained in the VEGFR-2 enzymatic inhibition assay), in accordance with the recommended daily intake of apigenin derivatives (4-24 mg) (Brasil, 2013). According with our previous results (Pereira et al., 2014), the A. montana hydroethanolic extract contains $48 \%(\mathrm{w} / \mathrm{w})$ of apigenin derivatives (Supplementary table).

All the subsequent analyses were performed with lyophilized yogurt samples obtained immediately after incorporation (right after the addition of the free or microencapsulated extracts) (t0), and after 3 days ( $\mathrm{t} 3$ ). The t0 and $\mathrm{t} 3$ yogurt samples were conditioned at $4{ }^{\circ} \mathrm{C}$ until analysis.

\subsubsection{Nutritional value of the yogurt samples}

For the assessment of the nutritional composition of the yogurt samples, moisture, protein, fat, carbohydrates and ash were determined following AOAC procedures (AOAC, 2005). The crude protein content (estimated as $\mathrm{N} \times 6.38$ ) was determined using the Kjeldahl method; the fat was determined by extracting a known weight of powdered sample with petroleum ether; the ash content was determined by incineration at $600 \pm 15^{\circ} \mathrm{C}$; and the total carbohydrates obtained by difference. Total energy was calculated as Energy $(\mathrm{kcal})=4 \times($ protein weight $(\mathrm{g})+$ carbohydrate weight $(\mathrm{g}))+9 \times($ lipid weight $(\mathrm{g}))$.

Free sugars were determined from defatted samples by HPLC coupled with a refraction index (RI) detector. The compounds were identified by chromatographic comparison with injected authentic standards, and quantification performed by the internal standard (melezitose) method. Sugars content was expressed in $\mathrm{g} / 100 \mathrm{~g}$ of the yogurt.

Fatty acids were analysed by gas-chromatography coupled with a flame ionization detector (GC-FID). The identification was made by comparison with the relative retention times of fatty acid methyl esters of standards. The results were expressed as relative percentages.

\subsubsection{VEGFR-2 phosphorylation inhibition}

The lyophilized yogurt samples $(1 \mathrm{~g})$ were extracted with $30 \mathrm{~mL}$ of ethanol: water $(80: 20 \mathrm{v} / \mathrm{v})$ at room temperature during $1 \mathrm{~h}$ under stirring. The obtained extract was filtered through a Whatman paper filter No. 4 and the remaining solid residue subjected to an additional extraction. The combined extracts were evaporated under reduced pressure in a rotatory evaporator until complete removal of ethanol. Finally, the evaporated extract was dissolved in water at a concentration of $8 \mathrm{mg} / \mathrm{mL}$ for the evaluation of VEGFR-2 phosphorylation inhibition according with the methodology described in Section 2.3.

\subsection{Statistical analysis}

All the assays were carried out in triplicate and the results expressed as mean values \pm standard deviation (SD), and maintaining the decimal places allowed by the magnitude of the standard deviation. An ANOVA with type III sums of squares was performed using the general linear model (GLM) procedure. The dependent variables were analysed using a 2-way ANOVA, with the factors "functionalizing type" (FT) and "storage time" (ST). When a statistically significant interaction $(\mathrm{FA} \times \mathrm{ST})$ was detected, the two factors were evaluated simultaneously by the estimated marginal means (EMM) plots for all the levels of each single factor. Alternatively, if no statistical significant interaction was verified, the means were compared using Tukey's honest significant difference (HSD) multiple comparison test to evaluate the FA effect, or by a $t$-student test to assess the effect of ST.

All statistical tests were performed at a 5\% significance level using IMB's SPSS (Statistics for Windows, version 22.0 (IBM Corp., Armonk, NY, USA).

\section{Results and discussion}

\subsection{VEGFR-2 phosphorylation inhibition by the A. montana extract}

In this work, the A. montana hydroethanolic extract was evaluated for its ability to interact with the VEGFR-2 kinase domain, using an enzymatic fluorescence resonance energy transfer (FRET) based assay. The results are presented in Fig. 1. The hydroethanolic extract showed ability to inhibit the enzymatic phosphorylation, and the obtained $\mathrm{IC}_{50}$ value was $63 \pm 3 \mu \mathrm{g} / \mathrm{mL}$. It was also possible to observe that the percentage of VEGFR-2 phosphorylation inhibition increased as the extract concentration increases. The sorafenib (positive control) showed a lower $\mathrm{IC}_{50}$ value, i.e. a high rate of VEGFR-2 phosphorylation inhibition. This synthetic drug was approved by the Food and Drug Administration (FDA) and has been commonly used for the treatment of pathological angiogenesis once it binds to receptors on the surface of the endothelial cells inhibiting, namely, the VEGFR-2. However, it reveals several toxicities for human organism. Diarrhea, fatigue, abdominal pain, hepatic toxicity, arterial and venous thrombotic events, gastric cancer and AVC are some of the side effects ascribed to sorafenib (Gotink \& Verheul, 2010).

It should be also highlighted that $A$. montana hydroethanolic extract gave a lower $\mathrm{IC}_{50}$ value (higher VEGFR-2 phosphorylation inhibition) than the methanolic extract $(269 \pm 9 \mu \mathrm{g} / \mathrm{mL})$ and infusion $(301 \pm 13 \mu \mathrm{g} / \mathrm{mL}$ ) obtained from Roman chamomile (Chamaemelum nobile L.) (Guimarães et al., 2016).

\subsection{Microencapsulation of the A. montana extract with alginate}

The A. montana hydroethanolic extract was microencapsulated with alginate using the atomization/coagulation process and following previously optimized conditions, as described in some former works of the authors (Dias, Barros et al., 2015; Martins et al., 2014; Ribeiro et al., 2016).

The produced microspheres were analysed by OM immediately after the atomization process (Fig. 2A) and after $4 \mathrm{~h}$ under stirring in a coagulation solution of calcium chloride (Fig. 2B). After atomization, the majority of the microspheres showed a characteristic morphology with a well-defined round shape. However, a few of them, in particular the ones with low size, revealed pear-like form. Nevertheless, along the contact period with the coagulation 


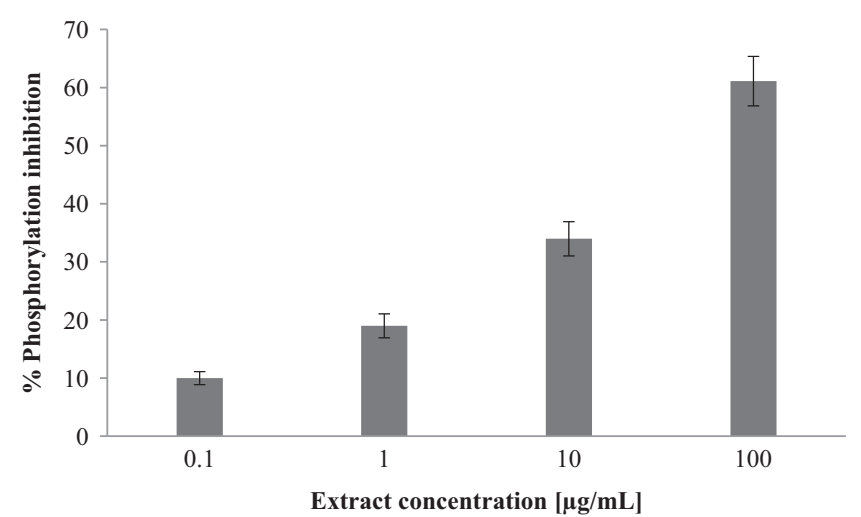

Fig. 1. Percentage of VEGFR-2 phosphorylation inhibition as a function of the $A$. montana extract concentration.

solution the number of microspheres with spherical morphology increased. Moreover, the microspheres were perfectly individualized (no agglomerates were detected). The size of the microparticles was estimated by $\mathrm{OM}$ as ranging between 14 and $88 \mu \mathrm{m}$, size slightly larger than the one obtained in previous works of the authors Martins et al. (2014), Dias, Barros et al. (2015) and Ribeiro et al. (2016). The lyophilized microparticles can be observed in Fig. 2C, showing a shape similar to the one observed for the hydrated forms obtained after the encapsulation process (round and pear-like form), although they showed a roughened surface due to the water removal, a consequence of the drying process. Additionally, the small brown spots observed in hydrated and lyophilized microspheres were associated with the presence of the extract inside the microparticles, in conformity with the work development by Ribeiro et al. (2016) and Caleja et al. (2016).

The encapsulation efficiency (EE), estimated through an indirect method based on the quantification of the non-encapsulated apigenin derivatives by HPLC-DAD, was determined as 100\% (the quantitative analysis of the coagulation and the two wash solutions revealed that the apigenin derivatives were present only in residual concentrations or absent).

\subsection{Yogurts functionalized with free and microencapsulated A. montana extracts}

\subsubsection{Nutritional value}

The yogurt samples were analysed for their nutritional composition regarding ash, fat, protein and carbohydrates (including individual quantification of galactose and lactose) contents, as well as
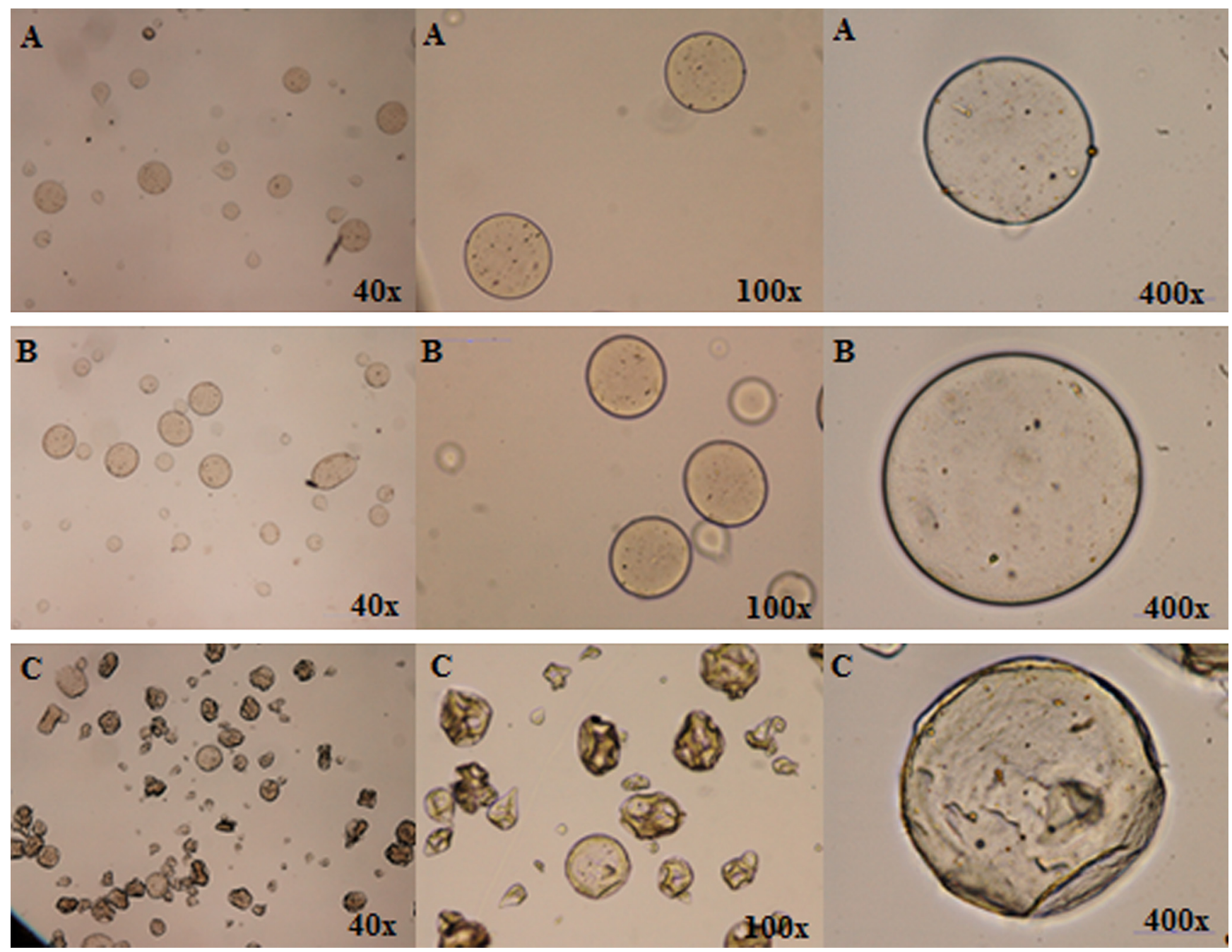

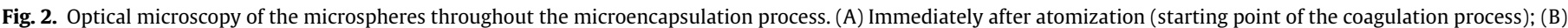

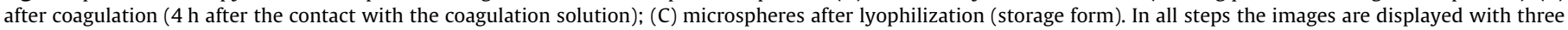
different magnifications (40, 100 and $400 \times)$. 
total energy. The studied "functionalized type" (FT) considered absent (no added extract), free and microencapsulated forms. The "storage time" (ST) considered 0 ( $\mathrm{t} 0$ ) and 3 days ( $\mathrm{t} 3$ ).

Before the study of each individual factor, it is necessary to analyse the possible interaction $(\mathrm{FT} \times \mathrm{ST})$ between the various factors under study. That is, check whether the effect of a given factor over the different levels of the second follows a specific trend. Thereby, for all the evaluated parameters, it was aimed to assess the ST effects regardless of having pure or functionalized yogurts, as well as evaluating the influence of FT, independently of the number of days kept in storage.

Table 1 shows the obtained results for macronutrients composition, individual sugars (galactose and lactose) and energetic value. It can be verified that the interaction was significant in the case of fat, protein and ash. Interestingly, these parameters were also not significantly affected by each individual factor in most cases, except protein, along ST, and fat, according to FT. Protein content was higher at initial ST (t0), while fat content was higher in the functionalized yogurts (both free and microencapsulated forms), although these differences cannot be unambiguously interpreted, due to the significant interaction between factors. For all the remaining parameters, the lack of a significant interaction allowed performing multiple comparisons for each individual factor, but their individual effects were only significant $(p$-value $<0.05)$ in the case of lactose (for ST), which proved to be significantly higher at $\mathrm{t} 0$, when compared to the value obtained at $\mathrm{t} 3$. All other parameters remained approximately invariable for both factors in study (ST and FT).

The results obtained are in agreement with other reports on yogurts (Caleja, Barros et al., 2016; Serafeimidou, Zlatanos, Kritikos, \& Tourianis, 2013). According with Serafeimidou et al. (2013), the yogurts prepared with cow and sheep milk had similar amounts of moisture and proteins, but lower ash content in comparison with the cow yogurt samples studied in the present work. However, ash values were in accordance with the ones reported by Caleja, Barros et al. (2016) for yogurts fortified with chamomile (Matricaria recutita L.) and fennel (Foeniculum vulgare Mill.) aqueous extracts. Furthermore, the same composition in galactose and lactose was described.

In the case of fatty acids (Table 2) the interaction between the factors was significant for all the analysed molecules. Thus, it is not possible to indicate unequivocal changes induced by each one of the factors. Nevertheless, the performed multiple comparisons indicated some general trends. The increase in ST induced a

Table 1

Nutritional value of the control yogurts and of those containing the extract (free or microencapsulated) at storage times of 0 and 3 days (mean \pm SD).

\begin{tabular}{|c|c|c|c|c|c|c|c|c|c|}
\hline & & \multirow{2}{*}{$\begin{array}{l}\text { Moisture (g/ } \\
100 \mathrm{~g})\end{array}$} & \multirow{2}{*}{$\begin{array}{l}\text { Fat }(\mathrm{g} / \\
100 \mathrm{~g})\end{array}$} & \multirow{2}{*}{$\begin{array}{l}\text { Protein (g/ } \\
100 \mathrm{~g})\end{array}$} & \multicolumn{3}{|c|}{ Carbohydrates (g/100 g) } & \multirow{2}{*}{$\begin{array}{l}\text { Ash }(\mathrm{g} / \\
100 \mathrm{~g})\end{array}$} & \multirow{2}{*}{$\begin{array}{l}\text { Energy (kcal/ } \\
100 \mathrm{~g})\end{array}$} \\
\hline & & & & & Galactose & Lactose & Total & & \\
\hline \multirow{2}{*}{ Storage time (ST) } & 0 days & $88 \pm 1$ & $2.6 \pm 0.2$ & $4.0 \pm 0.1$ & $0.5 \pm 0.1$ & $3.9 \pm 0.4$ & $4 \pm 1$ & $0.6 \pm 0.1$ & $57 \pm 2$ \\
\hline & 3 days & $89 \pm 1$ & $2.7 \pm 0.2$ & $3.8 \pm 0.1$ & $0.6 \pm 0.1$ & $3.4 \pm 0.4$ & $4 \pm 1$ & $0.6 \pm 0.1$ & $57 \pm 3$ \\
\hline$p$-value $(\mathrm{n}=27)$ & $t$-Student test & 0.054 & 0.065 & $<0.001$ & 0.284 & $<0.001$ & 0.108 & 0.062 & 0.394 \\
\hline \multirow{3}{*}{$\begin{array}{l}\text { Functionalization type } \\
\text { (FT) }\end{array}$} & Absent & $88 \pm 1$ & $2.4 \pm 0.1$ & $3.9 \pm 0.2$ & $0.6 \pm 0.1$ & $3.7 \pm 0.4$ & $4 \pm 1$ & $0.6 \pm 0.1$ & $56 \pm 2$ \\
\hline & Free extract & $89 \pm 1$ & $2.9 \pm 0.1$ & $3.9 \pm 0.1$ & $0.5 \pm 0.1$ & $3.7 \pm 0.4$ & $4 \pm 1$ & $0.5 \pm 0.1$ & $58 \pm 3$ \\
\hline & $\begin{array}{l}\text { Microencapsulated } \\
\text { extract }\end{array}$ & $89 \pm 1$ & $2.7 \pm 0.1$ & $3.9 \pm 0.1$ & $0.6 \pm 0.1$ & $3.6 \pm 0.5$ & $4 \pm 1$ & $0.6 \pm 0.1$ & $57 \pm 2$ \\
\hline$p$-value $(\mathrm{n}=18)$ & Tukey's HSD test & 0.352 & $<0.001$ & 0.762 & 0.205 & 0.801 & 0.308 & 0.051 & 0.090 \\
\hline $\mathrm{ST} \times \mathrm{FT}(\mathrm{n}=54)$ & $p$-value & 0.756 & 0.007 & $<0.001$ & 0.214 & 0.506 & 0.506 & 0.007 & 0.819 \\
\hline
\end{tabular}

Table 2

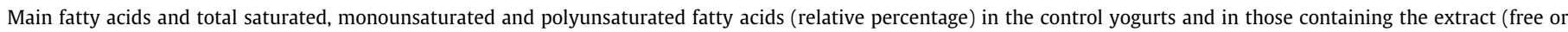
microencapsulated) at storage times of 0 and 3 days (mean \pm SD).

\begin{tabular}{|c|c|c|c|c|c|c|c|c|c|c|c|c|c|}
\hline & & $\mathrm{C} 4: 0$ & C6:0 & C10:0 & $\mathrm{C} 12: 0$ & $\mathrm{C} 14: 0$ & $\mathrm{C} 16: 0$ & C18:0 & $\mathrm{C} 18: 1$ & C18:2 & SFA & MUFA & PUFA \\
\hline \multirow[t]{2}{*}{ Storage time(ST) } & 0 days & $2 \pm 1$ & $2.4 \pm 0.4$ & $3.3 \pm 0.2$ & $3.7 \pm 0.1$ & $11 \pm 1$ & $31 \pm 1$ & $11 \pm 1$ & $24 \pm 1$ & $3.1 \pm 0.2$ & $69 \pm 1$ & $27 \pm 1$ & $4.6 \pm 0.2$ \\
\hline & 3 days & $3 \pm 1$ & $2.8 \pm 0.2$ & $3.2 \pm 0.2$ & $3.5 \pm 0.2$ & $11 \pm 1$ & $30 \pm 1$ & $11 \pm 1$ & $24 \pm 1$ & $3.2 \pm 0.2$ & $68 \pm 1$ & $27 \pm 1$ & $4.7 \pm 0.4$ \\
\hline$p$-value $(\mathrm{n}=27)$ & $t$-Student test & $<0.001$ & $<0.001$ & 0.059 & $<0.001$ & 0.062 & 0.002 & 0.485 & 0.473 & 0.702 & 0.216 & 0.345 & 0.160 \\
\hline \multirow{3}{*}{$\begin{array}{l}\text { Functionalization } \\
\text { type (FT) }\end{array}$} & Absent & $2.6 \pm 0.4$ & $2.7 \pm 0.2$ & $3.2 \pm 0.1$ & $3.5 \pm 0.2$ & $11 \pm 1$ & $30 \pm 1$ & $12 \pm 1$ & $24 \pm 1$ & $3.2 \pm 0.2$ & $68 \pm 1$ & $27 \pm 1$ & $4.8 \pm 0.3$ \\
\hline & Free extract & $2.3 \pm 0.5$ & $2.3 \pm 0.4$ & $3.5 \pm 0.1$ & $3.8 \pm 0.1$ & $11 \pm 1$ & $31 \pm 1$ & $11 \pm 1$ & $24 \pm 1$ & $3.1 \pm 0.2$ & $69 \pm 1$ & $27 \pm 1$ & $4.5 \pm 0.3$ \\
\hline & $\begin{array}{l}\text { Microencapsulated } \\
\text { extract }\end{array}$ & $3.6 \pm 0.2$ & $2.8 \pm 0.2$ & $3.1 \pm 0.2$ & $3.6 \pm 0.1$ & $11 \pm 1$ & $30 \pm 1$ & $11 \pm 1$ & $24 \pm 1$ & $3.1 \pm 0.2$ & $69 \pm 1$ & $27 \pm 1$ & $4.6 \pm 0.3$ \\
\hline$p$-value $(\mathrm{n}=18)$ & Tukey's HSD test & $<0.001$ & $<0.001$ & $<0.001$ & 0.001 & 0.055 & 0.061 & $<0.001$ & 0.080 & 0.085 & 0.064 & 0.236 & 0.056 \\
\hline $\mathrm{ST} \times \mathrm{FT}(\mathrm{n}=54)$ & $p$-value & $<0.001$ & $<0.001$ & 0.004 & $<0.001$ & $<0.001$ & $<0.001$ & $<0.001$ & $<0.001$ & $<0.001$ & $<0.001$ & $<0.001$ & $<0.001$ \\
\hline
\end{tabular}

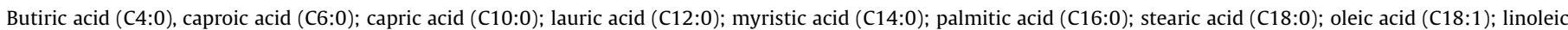

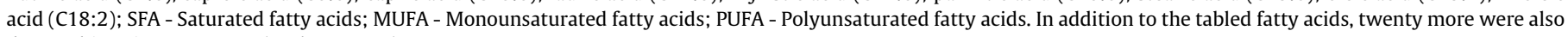
detected in minor amounts (each one $<2 \%$ ).

Table 3

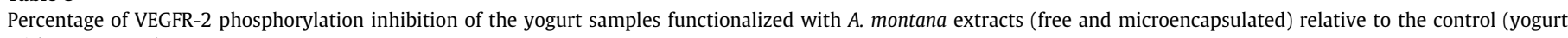
without extracts).

\begin{tabular}{|c|c|c|c|c|}
\hline & \multirow[t]{2}{*}{ Storage time (days) } & \multicolumn{3}{|c|}{ VEGFR-2 phosphorylation inhibition } \\
\hline & & $1 \mu \mathrm{g} / \mathrm{mL}$ & $10 \mu \mathrm{g} / \mathrm{mL}$ & $100 \mu \mathrm{g} / \mathrm{mL}$ \\
\hline Free extract & $\begin{array}{l}0 \\
3\end{array}$ & $\begin{array}{l}0.99 \pm 0.01 \\
2.44 \pm 0.06\end{array}$ & $\begin{array}{l}1.80 \pm 0.03 \\
3.12 \pm 0.05\end{array}$ & $\begin{array}{l}5.10 \pm 0.03 \\
0.85 \pm 0.05\end{array}$ \\
\hline Microencapsulated extract & $\begin{array}{l}0 \\
3\end{array}$ & $\begin{array}{l}1.31 \pm 0.06 \\
1.09 \pm 0.02\end{array}$ & $\begin{array}{l}1.84 \pm 0.07 \\
3.05 \pm 0.01\end{array}$ & $\begin{array}{l}4.13 \pm 0.03 \\
\sim 0\end{array}$ \\
\hline
\end{tabular}


slight increase in C4:0, C6:0 and C12:0 percentages, and minor reductions in $\mathrm{C} 12: 0$ and $\mathrm{C} 16: 0$ percentages. The remaining fatty acids proportions remained nearly constant. In what concerns FT effect, yogurts incorporated with the microencapsulated extract showed higher values of $\mathrm{C} 4: 0$ and $\mathrm{C6}: 0$, while those incorporated with the free extract showed higher percentages of C10:0 and C12:0. Finally, the control yogurts (yogurts absent of extract) showed slightly higher percentages of C18:0. All the other fatty acids, kept their overall percentages roughly constant, either in response to ST and FT factors, which indicates that the fatty acids profile suffer only slight changes. The general proportions (SFA > MUFA > PUFA) are in general agreement with previous works (Serafeimidou et al., 2013).

\subsubsection{Evaluation of the VEGFR-2 phosphorylation inhibition}

The yogurt functionalized with the free and microencapsulated extracts were evaluated for their potential VEGFR-2 phosphorylation inhibition. In general, yogurt samples added with the extract, in both free and microencapsulated forms, revealed very low inhibition ability (low inhibition percentages) (Table 3 ).

The absence, or scarcity, of VEGFR-2 phosphorylation inhibition observed for the yogurt samples prepared with the free extract was not foreseen based on its ascribed potential and the used amount $\left(2 \times \mathrm{IC}_{50}\right)$, which was also chosen to guarantee the recommended daily intake of apigenin derivatives. Due to this observation, a sample yogurt 20-fold more concentrate was prepared. The main objective was to evaluate the influence of the extract concentration on the VEGFR-2 phosphorylation activity of the prepared yogurt. However, the obtained results (data not shown) revealed, once again, very low inhibition percentages pointing out for the extract degradation and/or bioactivity loss. In fact, proteins, the predominant constituents of the yogurt matrix, present ability to conjugate with phenolic compounds (major constituents of the hydroethanolic extract) leading to bioavailability loss (Ozdal, Capanoglu, \& Altay, 2013).

When the microencapsulated forms were used, the determined VEGFR-2 phosphorylation inhibition was also absent, or scarce. In fact, the extract was, in this case, protected inside the alginate microspheres, material reported as stable in acid $\mathrm{pH}$ conditions (Cui, Goh, Kim, Choi, \& Lee, 2000), thus effective to protect it in contact with the yogurt, an acidic food matrix (Caleja, Barros et al., 2016). This behavior was also reported by Ribeiro et al. (2016) in cottage cheese functionalized with rosemary extracts microencapsulated in alginate microspheres. This procedure is, in principle, effective to avoid the loss of bioavailability during the shelf life of the product, thus until its ingestion and release in slight alkaline medium (intestinal conditions) due to the disruption of the alginate microparticles.

\section{Conclusions}

A. montana hydroethanolic extract, an extract rich in apigenin derivatives (weight content of $48 \%$, as reported in a previous work of the group (Pereira et al., 2014), revealed VEGFR-2 phosphorylation inhibition ability. The extract was successfully encapsulated in an alginate matrix, being incorporated in yogurts presenting nutritional properties similar to the ones incorporated with free extract or without extract (control sample). However, after incorporation of the free extract in yogurts, the antiangiogenic activity was not effective since only minor antiangiogenic ability was detected, independently of the used concentration. For the microencapsulated forms, and based on the successful applied microencapsulation process, the extract protection in acidic medium was expected, thus supporting the absence of the antiangiogenic activity of the produced yogurts. Accordingly, more studies are neces- sary to understand the stability of the bioactive compounds of the extract, namely their interactions with the food matrix constituents and behavior (for both free and microencapsulated forms) under simulated gastrointestinal conditions in order to develop functional foods with effective chemopreventive effects against pathological angiogenesis.

\section{Acknowledgements}

The authors are grateful to the Foundation for Science and Technology (FCT, Portugal) and FEDER for CIMO (UID/AGR/00690/2013) financial support. To POCI-01-0145-FEDER-006984 (LA LSRE-LCM) funded by ERDF through POCI-COMPETE2020 and FCT. To NORTE01-0145-FEDER-000006, funded by NORTE 2020, under PT2020 through ERDF. L. Barros, R.C. Calhelha and J.C.M. Barreira acknowledge the FCT for their post-doctoral grants (SFRH/BPD/107855/2015, SFRH/BPD/68344/2010 and SFRH/BPD/72802/2010, respectively). The authors also thank Ana Maria Carvalho for providing Arenaria montana L. samples.

\section{Appendix A. Supplementary material}

Supplementary data associated with this article can be found, in the online version, at http://dx.doi.org/10.1016/j.jff.2017.09.027.

\section{References}

AOAC (2005). Official methods of analysis of AOAC international. In W. Horwitz, \& G. Latimer (Eds.) (18th ed.) Gaithersburg, MD: AOAC International.

Banerjee, K., \& Mandal, M. (2015). Oxidative stress triggered by naturally occurring flavone apigenin results in senescence and chemotherapeutic effect in human colorectal cancer cells. Redox Biology, 5, 153-162.

Bigliardi, B., \& Galati, F. (2013). Innovation trends in the food industry. The case of functional foods. Trends in Food Science E Technology, 31, 118-129.

Brasil (2013). Agência Nacional de Vigilância Sanitária (ANVISA). Consulta Pública n - 14, de 14 de maio. Diário Oficial da União (D.O.U) de 15 de maio. Relator: Dirceu Brás Aparecido Barbano.

Budhraja, A., Gao, N., Zhang, Z., Son, Y., Cheng, S., Wang, X., ... Shi, X. (2012). Apigenin induces apoptosis in human leukemia cells and exhibits anti-leukemic activity in vivo. Molecular Cancer Therapeutics, 11, 132-142.

Caleja, C., Barros, L., Antonio, A. L., Carocho, M., Oliveira, M. B. P. P., \& Ferreira, I. C. F. R. (2016). Fortification of yogurts with different antioxidant preservatives: A comparative study between natural and synthetic additives. Food Chemistry, $210,262-268$.

Caleja, C., Ribeiro, A., Barros, L., Barreira, J. C. M., Antonio, A. L., Oliveira, M. B. P. P., ... Ferreira, I. C. F. R. (2016). Cottage cheeses functionalized with fennel and chamomile extracts: Comparative performance between free and microencapsulated forms. Food Chemistry, 199, 720-726.

Choudhury, D., Ganguli, A., Dastidar, D. G., Acharya, B. R., Das, A., \& Chakrabarti, G. (2013). Apigenin shows synergistic anticancer activity with curcumin by binding at different sites of tubulin. Biochimie, 95, 1297-1309.

Cui, J., Goh, J., Kim, P., Choi, S., \& Lee, B. (2000). Survival and stability of bifidobacteria loaded in alginate poly-l-lysine microparticles. International Journal of Pharmaceutics, 210,51-59.

Dias, I., Barros, L., Fernandes, I., Ruphuy, G., Oliveira, M. B. P. P., Santos-Buelga, C. Ferreira, I. C. F. R. (2015). A nutraceuticals formulations based on Fragaria vesca L. vegetative parts: characterization of the bioactives and application in kcarrageenan gelatina. Journal of Functional Foods, 16, 243-255.

Dias, M. I., Ferreira, I. C. F. R., \& Barreiro, M. F. (2015). Microencapsulation of bioactives for food applications. Food E Function. http://dx.doi.org/10.1039/ c4fo01175a.

Fan, T. P., Yeh, J. C., Leung, K. W., Yue, P. Y., \& Wong, R. N. (2006). Angiogenesis: From plants to blood vessels. Trends Pharmacological Sciences, 27, 297-309.

Gotink, K. J., \& Verheul, H. M. W. (2010). Anti-angiogenic tyrosine kinase inhibitors: What is their mechanism of action? Angiogenesis, 13, 1-14.

Guimarães, R., Calhelha, R. C., Froufe, H., Abreu, R., Carvalho, A. M., Queiroz, M. J. R. P., \& Ferreira, I. C. F. R. (2016). Wild Roman chamomile extracts and phenolic compounds: Enzymatic assays and molecular modelling studies with VEGFR-2 tyrosine kinase. Food and Function, 7, 79-83.

He, J., Ning, C., Wang, Y., Ma, T., Huang, H., Ge, Y., ... Jiang, Y. (2015). Natural plant flavonoid apigenin directly disrupts Hsp90/Cdc37 complex and inhibits pancreatic cancer cell growth and migration. Journal of Functional Foods, 18, 10-21.

Heleno, S., Martins, A., Queiroz, M. J. R. P., \& Ferreira, I. C. F. R. (2015). Bioactivity of phenolic acids: Metabolites versus parent compounds: A review. Food Chemistry, 173, 501-513.

Johnson, J. L., \& Mejia, E. G. (2013). Interactions between dietary flavonoids apigenin or luteolin and chemotherapeutic drugs to potentiate anti-proliferative effect 
on human pancreatic cancer cells, in vitro. Food and Chemical Toxicology, 60, 83-91.

Kim, B. R., Jeon, Y. K., \& Nam, M. J. (2011). A mechanism of apigenin-induced apoptosis is potentially related to anti-angiogenesis and anti-migration in human hepatocellular carcinoma cells. Food and Chemical Toxicology, 49, 1626-1632.

Lefort, É. C., \& Blay, J. (2013). Apigenin and its impact on gastrointestinal cancers. Molecular Nutrition \& Food Research, 57, 126-144.

Losso, J. N. (2007). In: J. N. Losso, F. Shahidi \& D. Bagchi (Eds.), Screening functional foods as inhibitors of angiogenesis biomarkers in anti-angiogenic functional and medicinal foods. CRC Press.

Martins, A., Barros, L., Carvalho, A., Santos-Buelga, C., Fernandes, I., Barreiro, F., \& Ferreira, I. C. (2014). Phenolic extracts of Rubus ulmifolius schott flowers: Characterization, microencapsulation and incorporation into yogurts as nutraceutical sources. Food Function, 5, 1091-1100.

Osada, M., Imaoka, S., \& Funae, Y. (2004). Apigenin suppresses the expression of VEGF, an important factor for angiogenesis, in endothelial cells via degradation of HIF-1 $\alpha$ protein. FEBS Letters, 575, 59-63.

Ozdal, T., Capanoglu, E., \& Altay, F. (2013). A review on protein-phenolic interactions and associated changes. Food Research International, 51, 954-970.

Patan, S. (2000). Vasculogenesis and angiogenesis as mechanisms of vascular network formation, growth and remodeling. Journal of Neuro-Oncology, 50, $1-15$.

Patel, H. J., Modi, S., Chiosis, G., \& Taldone, T. (2011). Advances in the discovery and development of heat-shock protein 90 inhibitors for cancer treatment. Expert Opinion on Drug Discovery, 6, 559-587.

Pereira, E., Barros, L., Calhelha, R. C., Dueñas, M., Carvalho, A. M., Santos-Buelga, C., \& Ferreira, I. C. F. R. (2014). Bioactivity and phytochemical characterization of Arenaria montana L. Food and Function, 5, 1848-1855.
Ribeiro, A., Caleja, C., Barros, L., Santos-Buelga, C., Barreiro, M. F., \& Ferreira, I. C. F. R. (2016). Rosemary extracts in functional foods: Extraction, chemical characterization and incorporation of free and microencapsulated forms in cottage cheese. Food and Function, 7, 2185-2196.

Saghiri, M. A. Asatourian, A. Orangi, J. Sorenson, C. M. \& Sheibani, N. (2015). Functional role of inorganic trace elements in angiogenesis - Part II: $\mathrm{Cr}, \mathrm{Si}, \mathrm{Zn}$, $\mathrm{Cu}$, and S. Critical Reviews in Oncology/Hematology, 96, 143-155.

Serafeimidou, A., Zlatanos, S., Kritikos, G., \& Tourianis, A. (2013). Change of fatty acid profile, including conjugated linoleic acid (CLA) content, during refrigerated storage of yogurt made of cow and sheep milk. Journal of Food Composition and Analysis, 31, 24-30.

Soares, P., Costa, R., Froufe, H. J. C., Calhelha, R. C., Peixoto, D., Ferreira, I. C. F. R., Queiroz, M. R. P. (2013). 1-Aryl-3-[4-(thieno[3,2-d]pyrimidin-4-yloxy)phenyl] ureas as VEGFR-2 Tyrosine Kinase Inhibitors: Synthesis, biological evaluation and molecular modelling studies. BioMed Research International. http://dx.doi. org/10.1155/2013/154856.

Stagos, D., Amoutzias, G. D., Matakos, A., Spyrou, A., Tsatsakis, A. M., \& Kouretas, D. (2012). Chemoprevention of liver cancer by plant polyphenols. Food and Chemical Toxicology, 50, 2155-2170.

Timité, G., Mitaine-Offer, A., Miyamoto, T., Tanaka, C., Mirjolet, J., Duchamp, O., \& Lacaille-Dubois, M. (2011). Unusual oleanane-type saponins from Arenaria montana. Phytochemistry, 72, 503-507.

Wang, Y., \& Huang, K. (2013). In vitro anti-inflammatory effect of apigenin in the Helicobacter pylori-infected gastric adenocarcinoma cells. Food and Chemical Toxicology, 53, 376-383.

Zhao, M. Ma, J., Zhu, H, Zhang X Du, Z Xu, Y \& Yu, X (2011). Apigenin inhibits proliferation and induces apoptosis in human multiple myeloma cells through targeting the trinity of CK2, Cdc37 and Hsp90. Molecular Cancer, 10, 2-14. 